\title{
CEsifo \\ WORKING

\section{The Cost of Public Funding with Direct and Indirect Taxation - a Revisit}

Bjart Holtsmark, Katinka Holtsmark 


\section{Impressum:}

CESifo Working Papers

ISSN 2364-1428 (electronic version)

Publisher and distributor: Munich Society for the Promotion of Economic Research - CESifo

$\mathrm{GmbH}$

The international platform of Ludwigs-Maximilians University's Center for Economic Studies and the ifo Institute

Poschingerstr. 5, 81679 Munich, Germany

Telephone +49 (0)89 2180-2740, Telefax+49 (0)89 2180-17845, email office@cesifo.de

Editor: Clemens Fuest

https://www.cesifo.org/en/wp

An electronic version of the paper may be downloaded

- from the SSRN website: www.SSRN.com

- from the RePEc website: $\quad$ www.RePEc.org

- from the CESifo website: https://www.cesifo.org/en/wp 


\title{
The Cost of Public Funding with Direct and Indirect Taxation - a Revisit
}

\begin{abstract}
The paper shows that the marginal cost of public funds (MCF) does not depend on whether public revenue is collected by taxation of consumer goods or income from factors supplied by households on the market. Atkinson and Stern (1974) concluded in their seminal paper that "[...] whether the Conventional Rule provides an under- or over-estimate depends on the choice of taxed good [....]." This conclusion has created confusion in the literature on the MCF and has been the basis for recent literature arguing that the standard measure of the MCF has weaknesses and should be replaced by alternative measures (Jacobs, 2018; Håkonsen, 1998). We show that the conclusion of Atkinson and Stern (1974) on this issue is not valid and is based on an error in their analysis.
\end{abstract}

JEL Codes: H200, H400, H500.

Keywords: marginal cost of public funds, taxation, Samuelson rule.

\author{
Bjart J. Holtsmark \\ Research Department \\ Statistics Norway \\ Oslo / Norway \\ Bjart.Holtsmark@ssb.no
}

\author{
Katinka Kristine Holtsmark* \\ Department of Economics \\ University of Oslo / Norway \\ k.k.holtsmark@econ.uio.no
}

*corresponding author

February 16, 2021

We are grateful to Paolo Giovanni Piacquadio for valuable comments and suggestions. 


\section{Introduction}

The article Atkinson and Stern (1974) represents an important contribution to the literature on public finance. However, one of their findings was that the marginal cost of public funding depends on the choice between taxation of factor income and taxation of consumer goods. Their conclusion on this issue is based on an error in their analysis that to our knowledge has never been corrected. The contribution of this paper is to untangle this error and to show that the marginal cost of public funding is not influenced by the choice between direct and indirect taxation.

The conclusion of Atkinson and Stern (1974) on this issue has caused confusion in the literature on the marginal cost of public funds (MCF). In both Håkonsen (1998), Jacobs and de Mooij (2015), and Jacobs (2018) the claimed sensitivity of the marginal costs of taxation with respect to the choice between taxation of consumption and taxation of factor income is emphasized as a serious weakness of the traditional MCF concept. Moreover, the alleged weakness of the concept is used as an argument in favor of using alternative measures of the cost of public funding. The present paper shows that the claimed weakness of the traditional MCF concept is based on an error.

The size of the MCF has consequences in a large range of policy areas. The MCF is an important factor related to public spending and may thus have farreaching consequences for decisions regarding public spending in general. For example, the MCF is typically used as a parameter in cost-benefit analyses for public projects, and the size will typically strongly affect the perceived costs of such projects. Moreover, the determinants of the MCF are central to the design of a good tax scheme. Correct, precise and reliable knowledge regarding the determinants of the MCF is therefore of importance to policy makers. In our view, this knowledge is also at the core of what the economics literature should provide.

To facilitate identification of the error in Atkinson and Stern (1974) that leads to their incorrect conclusion, we use the same stylized model that was used by Atkinson and Stern (1974). The model allows investigation of second-best taxation and public goods provision in a simple, yet fairly general setting with a set of households optimizing their consumption and supply of labour or other production factors on the market. We show how the costs of taxation affect second- 
best provision of the public good, and that these costs - and their consequences for public goods provision - are independent of the choice between taxation of consumption and of factor income.

The intuition behind the result is simple. A consumption tax has the same effects on economic behaviour as an income tax, as long as we compare the same effective tax rates. Therefore, the deadweight loss from taxation must also be the same in the two cases. The choice between an income tax and a consumption tax therefore does not influence the cost of taxation or provision of public goods in the second best.

An important starting point for Atkinson and Stern (1974) was the discussion in Pigou (1947) on the optimal size of the public sector when taxes cause "damage" to economic efficiency. According to Pigou (1947, p. 34) such "damage" means that

"[...] expenditure ought not to be carried so far as to make the real yield of the last unit of resources expended by the government equal to the real yield of the last unit left in the hands of the representative citizen."

The original Samuelson rule for provision of public goods states that firstbest public expenditure is such that the sum of the marginal rates of substitution between public goods and private consumption equals the marginal rate of transformation (Samuelson, 1954). A reasonable interpretation of Pigou's statement is that the Samuelson rule represents inefficiently high public expenditure when taxation is distortionary. Stiglitz and Dasgupta (1971) showed that his conclusion must be nuanced. They found that (p. 159)

\footnotetext{
"if there is only one consumption good and one factor, labour, whether the Conventional Rule represents an under or over supply depends simply on whether the supply curve of labour is backward bending or upward sloping".
}

With reference to this result, however, Atkinson and Stern (1974, p. 120) claimed that Stiglitz and Dasgupta (1971) 
"overlook the important consideration that their result depends on the choice of which goods are taxed."

Moreover, on page 126 Atkinson and Stern concluded that

"[...] whether the Conventional Rule provides an under- or over-estimate depends on the choice of taxed good [....]." 1

Essentially, Atkinson and Stern (1974) claimed that - all else equal - the cost of an incremental increase in the provision of a public good is lower if the good is financed by a labour income tax than if a tax on consumption is used. We show in this paper that this conclusion is incorrect and follows from an error in their analysis, and we identify this error. With the model applied by Atkinson and Stern (1974) the distortionary effects of a consumption tax are exactly the same as the distortionary effects of an income tax. The two tax instruments will therefore lead to the same MCF and the same modification of the Samuelson rule.

Despite the error, it should be emphasized that Atkinson and Stern (1974) represents an important contribution to the public finance literature. The importance of their contribution is well described by Ballard and Fullerton (1992); see also for example Dahlby (1998). An important contribution was to demonstrate the need for a distinction between two different questions that could easily be confused. On the one hand, there is the question of the appropriate measure of the marginal cost of public funding; on the other, the appropriate output level for public goods provision. They show that even if the cost of public funding is less than one on the margin, public goods provision can be smaller in the second-best than in the first-best.

However, to our knowledge, the mistaken conclusion of Atkinson and Stern (1974) has not been corrected in the literature. On the contrary, the conclusion has been adopted in later and in more recent literature. For example, Boadway and Keen (1993, p. 473) build on Atkinson and Stern (1974) when they write that

"different choices of untaxed numeraire may give rules for the optimal provision of the public good that diverge from the Samuelson Rule in opposite directions."

\footnotetext{
${ }^{1}$ Atkinson and Stern (1974) used the term Conventional Rule for what we today usually label the Samuelson rule attributable to Samuelson (1954).
} 
Furthermore, Håkonsen (1998), Jacobs and de Mooij (2015), and Jacobs (2018) conclude that the alleged sensitivity with respect to the choice of taxed good reveals a serious weakness in the traditional measure of the MCF. Based on this conclusion, they discuss and propose alternative measures. Jacobs (2018) states that:

"[...] the most regularly used definition [of the MCF], e.g., in Atkinson and Stern (1974), Ballard and Fullerton (1992), and Sandmo (1998), [is] highly sensitive to the choice of the untaxed numeraire good"

and uses this claimed weakness of the traditional MCF concept as an argument in favour of an alternative concept. Based on this alternative MCF concept, Jacobs (2018) further concludes that the MCF is equal to one in the second-best allocation and that no correction of the Samuelson rule is necessary. Jacobs and de Mooij (2015) build on the same arguments when they argue that Pigouvian taxes should not be adjusted to take the MCF into account.

The paper is organized as follows. Section 2 presents a basic model of publicgoods provision and taxation with the same set up as used by Atkinson and Stern (1974). Section 2.1 considers first-best provision of public goods as a benchmark, while Section 2.2 examines the second-best solution with taxation and presents the modified Samuelson rule and the main finding. Section 2.3 provides a graphical illustration of our results. Section 3 provides a conclusion.

\section{Model and results}

The model presented in the following is the same as was used by Atkinson and Stern (1974), because we want our results on the size of the the MCF to be as easily comparable to theirs as possible.

The economy considered is assumed to have the production constraint

$$
G(\mathbf{X}, e)=0,
$$

where $\mathbf{X}=\left(X_{1}, \ldots, X_{n}\right)$ is a vector of the $n$ private goods consumed and factors supplied, while $e$ is consumption - and provision - of a public good. Assume 
throughout, without loss of generality, that if good $i$ is a consumption good, then $\mathrm{X}_{i} \geq 0$, and if good $i$ it is a supplied factor, then $X_{i} \leq 0$. Let $G_{i}>0$ denote the first derivative of the function $G(\cdot)$ with respect to argument $i=1, \ldots, n, e$. Let $p_{i} \geq 0$ be the prevailing equilibrium producer price of good $i$, and define good 1 as numeraire so that $p_{1}=1$. Moreover, assume, as a normalization, that $G_{1}=1$. All firms in the market are competitive, and there are constant returns to scale in production, which then means that we must have $G_{i}=p_{i}$ for $i=1, . ., n$ in the market equilibrium.

Let $\mathbf{x}=\left(x_{1}, \ldots, x_{n}\right)$ be the vector of goods consumed and factors supplied by each individual household and $\mathbf{q}=\left(q_{1}, \ldots, q_{n}\right)$ be the vector of consumer prices. There are $h$ identical households maximizing utility $u(\mathbf{x}, e)$, subject to the budget constraint $\mathbf{q} \mathbf{x}=0$. It follows that $x_{i}=X_{i} / h$ for all $i$. The utility function is increasing and concave in all arguments. Let $u_{i}>0$ denote the marginal utility of good or factor $i$ for $i=1, \ldots, n$ and let $u_{e}$ denote the marginal utility of the public good.

To produce the public good, $e$, the government must reallocate resources. This is done by raising a total tax revenue of $\mathbf{t X}$, where $\mathbf{t}=\left(t_{1}, \ldots, t_{n}\right)$ is the vector of taxes such that $q_{i}=p_{i}+t_{i}, i=1, \ldots, n .^{2}$ If good $i$ is a consumption good, then $t_{i} \geq 0$ and if good $i$ is a factor, then $t_{i} \leq 0$.

\subsection{The first-best allocation}

The first-best allocation of resources in the economy is given by the solution to the following problem:

$$
\max _{\mathbf{x}, e} h \cdot u(\mathbf{x}, e) \quad \text { s.t. } \quad G(h \mathbf{x}, e)=0
$$

This problem is solved by the $n$ first-order conditions:

$$
h \frac{u_{e}}{u_{i}}=\frac{G_{e}}{G_{i}}, \forall i
$$

\footnotetext{
${ }^{2}$ We adopted the approach applied by Atkinson and Stern (1974) when modelling with specific (quantity) taxes. In more recent literature it is more common to model with ad valorem taxes, with $q_{i}=\left(1+t_{i}\right) p_{i}$, see for example Dahlby (1998), Christiansen (2007), Sandmo (1998), Jacobs (2018).
} 
which, together with the resource constraint, determine optimal consumption and supply of all private goods and optimal provision of the public good. Equation (2) states the well-known Samuelson rule for provision of a public good: The marginal cost of producing the good should equal the aggregate marginal value of access to the good for all households.

\subsection{The second-best allocation}

Households maximize utility, $u(\mathbf{x}, e)$, given their budget constraint. The Lagrange function can be written as follows, with subscript $h$ for households:

$$
L_{h}=u(\mathbf{x}, e)-\alpha \sum_{i} \frac{q_{i}}{q_{1}} x_{i}
$$

where $\alpha$ is the Lagrange multiplier. The first-order conditions become:

$$
u_{j}=\alpha \frac{q_{j}}{q_{1}}, \forall j
$$

The first-order conditions determine equilibrium demand and supply of all private goods, $\mathbf{X}(\mathbf{q}, e)=h \mathbf{x}(\mathbf{q}, e)$. Furthermore, equilibrium consumption, together with provision of the public good, determine the equilibrium Lagrange multiplier $\alpha(\mathbf{q}, e)$, which equals $u_{1}$, the marginal utility of good 1 . With the chosen setup, $\alpha$ also represents the marginal utility of income (net of taxes) as $p_{1}=1$. The representative household's value function is given by $v(\mathbf{q}, e)$. The derivatives of the value function with respect to public good supply and tax rates are given by:

$$
v_{e}=u_{e}, \quad v_{q_{i}}=-\alpha \frac{1}{q_{1}} x_{i}, \forall i
$$

Note that, in contrast, Atkinson and Stern (1974, p 122) state that $v_{q_{i}}=-\alpha x_{i}$, for all $i$, which implies an interpretation of $\alpha$ different from ours if there is a tax on good 1.

Given the households' behaviour, the government sets the taxes and the 
supply of the public good to solve the following maximization problem:

$$
\max _{\mathbf{q}, e} h v(\mathbf{q}, e) \quad \text { s.t. } \quad G(\mathbf{X}(\mathbf{q}, e), e)=0
$$

The government's Lagrange function can be written:

$$
L_{g}=h \cdot v(\mathbf{q}, e)-\mu G(\mathbf{X}(\mathbf{q}, e), e)
$$

where $\mu$ is the Lagrange multiplier. The first-order conditions are given by:

$$
\begin{aligned}
& h v_{e}-\mu\left[\sum_{i} G_{i} \frac{\partial X_{i}}{\partial e}+G_{e}\right]=0 \\
& h v_{q_{j}}-\mu \sum_{i=1}^{n} G_{i} \frac{\partial X_{i}}{\partial q_{j}}=0, \forall j .
\end{aligned}
$$

A modified Samuelson rule follows from reorganizing Equation (4). Divide the equation by $\alpha$, use $G_{i}=p_{i}$ and that it follows from the household budget constraint that

$$
-\sum_{i} p_{i} \frac{\partial X_{i}}{\partial e}=\sum_{i} t_{i} \frac{\partial X_{i}}{\partial e}
$$

The modified Samuelson rule can be written as follows:

$$
\frac{\alpha}{\mu} h \frac{u_{e}}{u_{1}}=G_{e}-\frac{\partial}{\partial e} \mathbf{t X}
$$

This equation applies irrespective of whether the numeraire good is taxed or not. By contrast, the corresponding Equation (3) in Atkinson and Stern (1974) applies only when $t_{1}=0$.

On the left-hand side of the modified Samuelson rule is the sum of the marginal willingness to pay across all households for the public good, adjusted by the multiplier $\alpha / \mu$. On the right-hand side is the unit cost in production of the public good minus the change in public revenue from a marginal increase in the public good supply. 
The size of the multiplier $\alpha / \mu$ depends on the distortionary effects of taxation. To what extent, and in what direction, the Samuelson rule should be modified to achieve the second-best solution depends of the size of this multiplier. To analyse the size of $\alpha / \mu$, we turn to Equation (5). ${ }^{3}$ Reorganizing using that $v_{q_{j}}=-\alpha x_{j} / q_{1}$, $G_{i}=p_{i}$ and the household budget constraint, the multiplier can be written as:

$$
\frac{\alpha}{\mu}=\left(1+t_{1}\right)\left(\frac{\frac{\partial}{\partial t_{j}} \mathbf{t X}}{X_{j}}\right), \forall j
$$

Equation (7) corresponds to Equation (4) in Atkinson and Stern (1974), which they used as the basis for their discussion of the size of the fraction $\mu / \alpha$, and their claim that whether $\mu / \alpha$ is less than or greater than 1 depends on the choice between a consumption tax and a tax on factor income. However, they did not include the first factor on the right-hand side, $\left(1+t_{1}\right)$, which means that their Equation (4) does not hold when good 1 is taxed. This explains why they reached their incorrect conclusion with regard to the sensitivity of the choice of taxed good. ${ }^{4}$ The mistake of Atkinson and Stern (1974) arises when they use their Equation (4) as if it holds generally, while in reality it only holds for $t_{1}=0$.

In the following, we will show that the choice between taxing consumer goods

\footnotetext{
${ }^{3}$ In more recent literature, the inverse of the multiplier, i.e. $\mu / \alpha$, is the standard measure of the MCF and usually included as a factor on the right-hand side of the equation (Sandmo, 1998; Gahvari, 2006; Kleven \& Kreiner, 2006; Kreiner \& Verdelin, 2012; Jacobs, 2018). $\mu$ represents the marginal value of public funds in units of utility, in the second-best allocation. Equivalently, $\mu$ represents the marginal cost of increasing taxation. This marginal cost includes both the direct cost in terms of resources reallocated from private consumption to government spending and the cost related to distortionary effects of taxation. By dividing by $\alpha$, which equals the marginal utility of spending one dollar on good 1, the measure is converted from welfare units to a multiplier representing the $\mathrm{MCF}$, to be used to adjust the costs of tax-funded projects.

${ }^{4}$ It might here be objected that Atkinson and Stern (1974) stated on page 122 that $\partial \mathrm{V} / \partial q_{i}=$ $-\alpha x_{i}$. This is consistent with the assumption that $\alpha \equiv u_{1} / q_{1}$. Then the term $\left(1+t_{1}\right)$ on the right-hand side of equation (7) vanishes. However, in that case, the modified Samuelson rule, in cases where the numeraire good is taxed, should be:

$$
\left(1+t_{1}\right) \frac{\alpha}{\mu} h \frac{u_{e}}{u_{1}}=\frac{G_{e}}{G_{1}}-\frac{\partial}{\partial e} \mathbf{t} \mathbf{X},
$$

which means that the multiplier becomes $\left(1+t_{1}\right) \alpha / \mu$. Hence, in this case, too, the right-hand side of equation $(7)$, with the term $\left(1+t_{1}\right)$ included, represents the true multiplier of the modified Samuelson rule.
} 
and taxing factor income is irrelevant for the size of the multiplier $\alpha / \mu$.

When considering the effect of the choice of taxed good, Atkinson and Stern (1974) turned to the two-good case with a single consumption good and one production factor, an approach frequently used in the literature. ${ }^{5}$ In the following we therefore also consider the two-good case. In Appendix A we show that our result also applies to a case with an unspecified number, $m$, of consumer goods and $n-m$ supplied factors.

In the following, let good 1 represent the consumer good and good 2 represent the supplied factor. First, it is useful to define the effective tax on factor income, given by:

$$
t \equiv \frac{t_{2}-p_{2} t_{1}}{1+t_{1}} \leq 0
$$

It follows from this definition that the public revenue is given by $t X_{2} \equiv t_{1} X_{1}+t_{2} X_{2}$ in equilibrium, and is thus determined only by $t$, not by the distribution of the tax burden between the consumption good and factor income.

For notational simplicity, define the relative consumer price $q \equiv q_{2} / q_{1}$. Given the effective tax on factor income, $t$, the size of the relative price $q$ is not influenced by the distribution of the tax burden between $t_{1}$ and $t_{2}$. As a result, the same is true for the household budget constraint and for demand and supply. Let $f_{1}(q, e)=$ $X_{1}\left(q_{1}, q_{2}, e\right)$ and $-f_{2}(q, e)=-X_{2}\left(q_{1}, q_{2}, e\right)$ represent demand for and supply of goods 1 and 2, respectively, expressed as functions of the relative price. The following proposition presents the main finding in this paper:

Proposition 1. Consider the two-good case. Let $X_{1}$ be private consumption and $-X_{2}$ be factor supply. The distortionary cost of taxation and, correspondingly, the multiplier in the Samuelson rule, $\alpha / \mu$, are independent of whether the consumption good or the supplied factor is taxed, and depend only on the effective tax rate on factor income, $t$, as defined by Equation (8). The multiplier is given by:

$$
\frac{\alpha}{\mu}=1+\frac{t}{X_{2}} \frac{\partial f_{2}(q, e)}{\partial q} .
$$

\footnotetext{
${ }^{5}$ See for example Browning, Gronberg, and Liu (2000), Sandmo (1998), Kreiner and Verdelin (2012), Kleven and Kreiner (2006), Kaplow (1996), Jacobs (2018), or Håkonsen (1998).
} 
Proof. Taking the derivative of the household budget constraint, expressed as $f_{1}(q, e)+q f_{2}(q, e)=0$, with respect to $q$, gives:

$$
\frac{\partial f_{1}}{\partial q}=-\left(q \frac{\partial f_{2}}{\partial q}+x_{2}\right)
$$

By definition of the functions $f_{1}(\cdot)$ and $f_{2}(\cdot)$ and use of (10) we have:

$$
\frac{\partial x_{1}}{\partial q_{1}}=\frac{\partial x_{1}}{\partial t_{1}}=-\frac{q_{2}}{q_{1}^{2}} \frac{\partial f_{1}}{\partial q}=\frac{q_{2}^{2}}{q_{1}^{3}} \frac{\partial f_{2}}{\partial q}+\frac{q_{2}}{q_{1}^{2}} x_{2}, \quad \frac{\partial x_{2}}{\partial q_{2}}=\frac{\partial x_{2}}{\partial t_{2}}=-\frac{1}{q_{1}} \frac{\partial f_{2}}{\partial q} .
$$

Note further that in the case of $t_{2}=0, t_{1}$ can be expressed in terms of $t$ as $t_{1}=-t /\left(p_{2}+t\right)=-t / q$. If $t_{1}=0$ we have $t_{2}=t$.

Both in the case where $j=1, t_{2}=0, t_{1}=-t /\left(p_{2}+t\right)$ and in the case where $j=2, t_{1}=0, t_{2}=t$, reorganizing Equation (7), gives that $\alpha / \mu$ can be expressed as in Equation (9).

Proposition 1 makes it clear that the effective tax rate $t$ determines the size of the multiplier in the modified Samuelson rule and that the choice between taxation of consumption and of factor income does not matter for the multiplier. It follows from Proposition 1 that, irrespective of the choice of taxed good, Stiglitz and Dasgupta (1971, p. 159) were correct in stating that

"[...] whether the conventional rule represents an under or over supply depends simply on whether the supply curve of labour is backward bending or upward sloping." ${ }^{6}$

\subsection{An illustration}

Our result is illustrated by Figure 1 for a two-good case with a single household and a linear resource constraint. The black and green solid lines are the household budget constraints before and after a tax is implemented, respectively.

\footnotetext{
${ }^{6}$ Atkinson and Stern (1974, p. 120) pointed to the unclear meaning of Stiglitz and Dasgupta's use of the expression under- or over-supply in this context, because different interpretations are possible. The question of the size of the multiplier in the modified Samuelson rule, which it is reasonable to assume that Stiglitz and Dasgupta had in mind, has to be distinguished from the question of the level of provision of public goods in first-best compared to second-best. Atkinson and Stern (1974) showed that the provision of public goods can be lower in second-best compared to first-best also in the case of a backward bending labour supply curve.
} 
The tax revenue, measured in units of good 1, for a given level of factor supply $X_{2}$, is the horizontal distance between the red dashed line and the solid black line. With a tax implemented, households choose point C. Tax revenue is then the distance CB.

Next, assume that the tax increases. The solid blue line is the budget constraint after the tax increase. Households then choose point E, with less factor supply compared to C. Thus, in this example it is implicitly assumed that the factor supply curve is upward sloping. ${ }^{7}$

With respect to Figure 1, it is also worth drawing attention to the following statement in Atkinson and Stern (1974, p. 123):

"The reason for the dependence of the sign on the choice of the taxed good is fairly clear: the "income" effect of taxation reduces the revenue from a consumption tax given normality but increases the revenue from a factor tax given normality of leisure."

In our view, this consideration is too partial. Figure 1 provides an illustration of the full equilibrium effects of taxes on both consumption and on factor income. Given the same effective tax change, the income effects and the substitution effects are the same in the two cases in the end, with the same effects on revenue.

The income effect of the tax increase leads to movement from point $\mathrm{C}$ to $\mathrm{D}$, which increases the revenue equal to the distance HD. This also applies with a consumption tax. The substitution effect reduces the revenue, and the final effect on total revenue of the tax change is equal to the distance EF, which is smaller than HD.

\section{Conclusion}

Atkinson and Stern (1974) stands out as an important contribution to the literature in public economics. The article shed new light on issues related to the costs of

\footnotetext{
${ }^{7}$ For the case with a backward-bending factor supply curve and $\mathrm{MCF}<1$, see the illustration in Ballard and Fullerton (1992, p. 123). They considered the case with a wage tax only and did not discuss whether the MCF is sensitive to the choice between factor income tax and consumption tax.
} 


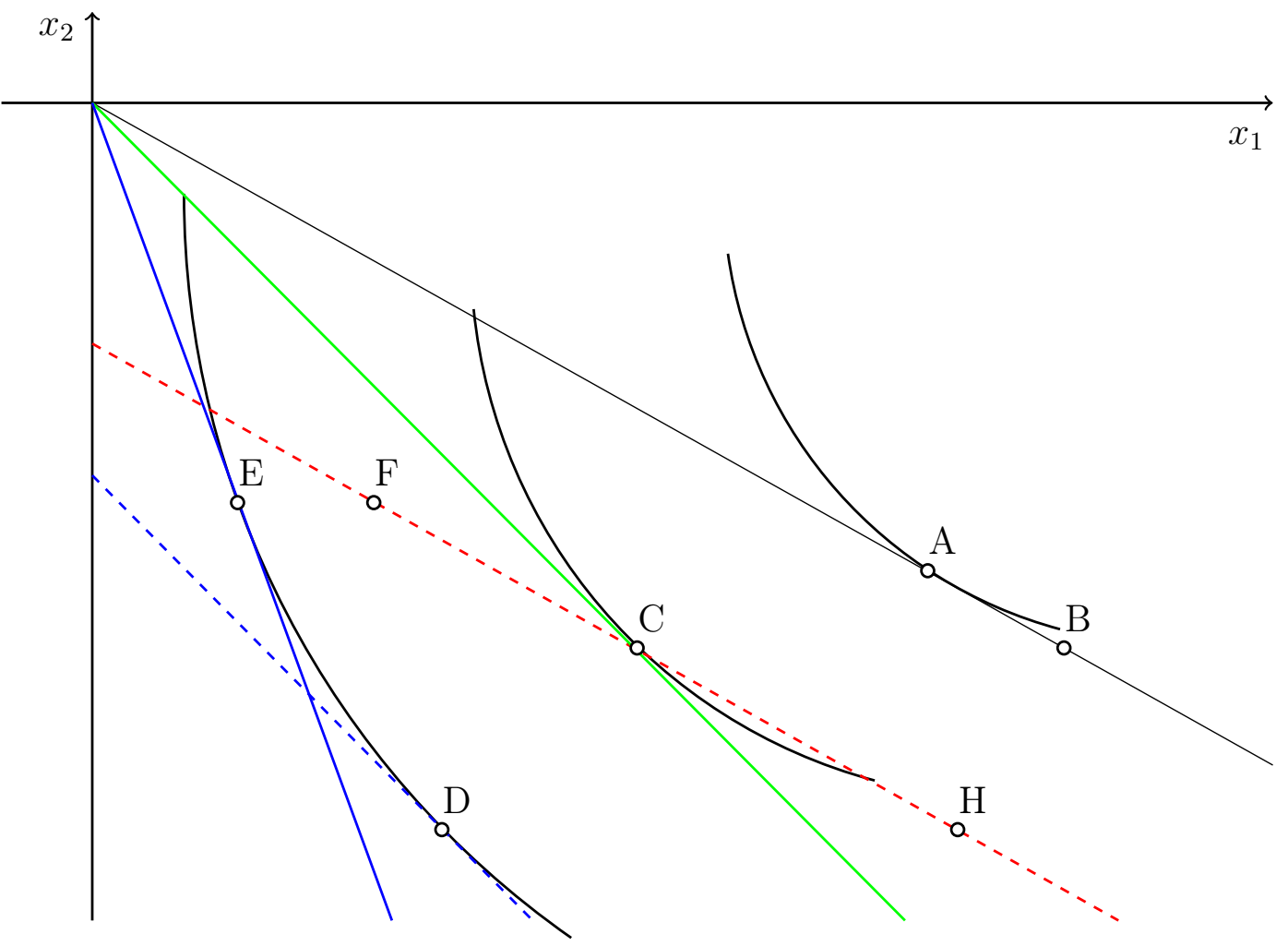

Figure 1: Tax increase in the two-good case. Point A represents the household consumption bundle without taxes, point $\mathrm{C}$ the case with a tax, and point $\mathrm{E}$ the case after the tax has been increased. The income effect $(\mathrm{C} \rightarrow D)$ and the substitution effect $(D \rightarrow E)$ are also illustrated. The income effect of the tax change increases the revenue by an amount equal to the distance HD irrespective of whether a consumption tax or a labour income tax is applied. The total effect on revenue is equal to the distance $\mathrm{EF}$. 
taxation and the appropriate output level of public goods. Atkinson and Stern showed why it is important to distinguish between the question of the size of "the appropriate benefit measure for incremental output of the public good" to be used in cost-benefit analyses and the appropriate output level for public goods. They also showed the importance of how the income effects of taxation might counteract the distortionary effects of taxation, and that we cannot rule out that even before the distributional effects of taxation are taken into account, the marginal costs of taxation can be less than 1 .

However, because Atkinson and Stern (1974) is such an important contribution to the literature, it is necessary to shed light on the mistaken conclusion that how the Samuelson rule should be modified depends on whether the consumer good or labour income is taxed.

We have shown in this paper that this conclusion is incorrect and is based on a miscalculation. More precisely, we have shown that the MCF is independent of whether the consumption good or the supplied factor is taxed. It follows that modified Samuelson rule does not depend on the choice of taxing consumer goods or labour supply.

To our knowledge, the mistaken conclusion of Atkinson and Stern (1974) has not been corrected in the literature. On the contrary, later contributions on the costs of taxation have adopted Atkinson and Stern's result and claimed that this reveals that the traditional MCF measure has a serious weakness, and this is used as an argument in favour of new MCF concepts; see Håkonsen (1998), Jacobs and de Mooij (2015), and Jacobs (2018).

The alleged weakness in the standard measure of the MCF is central to Jacobs' justification of his conclusion that this measure should not be applied in social cost-benefit analysis. We have shown in this paper that the standard MCFmeasure does not have a weakness related to the sensitivity with respect to the choice between taxing consumer goods or factor income.

The economics literature should provide knowledge and understanding of the size and interpretation of the MCF that is precise and correct. The MCF is important in a large range of policy decisions. Mistakes in calculating or interpreting the MCF therefore are not only of theoretical interest, but will also affect practical policy. Thus, it is important to correct the mistaken conclusion made in Atkinson 
and Stern (1974).

\section{Appendices}

\section{A The case with many consumer goods and many factors supplied}

This appendix shows that the result of Proposition 1 applies also to a more general case with unspecified numbers of consumer goods and factors supplied.

Assume that $m$ goods are consumed and $(n-m)$ factors supplied. Let $\mathbf{X}_{c}=\left(X_{1}, \ldots, X_{m}\right)$ be the vector of the private goods consumed while $\mathbf{X}_{s}=$ $\left(X_{m+1}, \ldots, X_{n}\right)$ is the vector of the factors supplied. It follows that $\mathrm{X}_{i} \geq 0, i=$ $1, . ., m$, and that $X_{i} \leq 0, i=m+1, . ., n$.

Let $\mathbf{x}_{c}=\left(x_{1}, \ldots, x_{m}\right)$ be the vector of the $m$ private goods consumed and $\mathbf{x}_{s}=\left(x_{m+1}, \ldots, x_{n}\right)$ the vector of the $n-m$ factors supplied by a single household. Correspondingly, let $\mathbf{q}_{c}=\left(q_{1}, \ldots, q_{m}\right)$ and $\mathbf{q}_{s}=\left(q_{m+1}, \ldots, q_{n}\right)$ be the vectors of consumer prices after-tax factor incomes.

We now include a set of ad valorem taxes and assume that there is a common tax rate $t_{c} \geq 0$ for goods consumed and a common tax rate for factors supplied $t_{s} \epsilon[0,-1)$ such that $q_{i}=\left(1+t_{c}\right) p_{i}, i=1, . ., m$, and $q_{i}=\left(1+t_{s}\right) p_{i}, i=m+1, . ., n$.

Next, define the effective tax rate:

$$
\tilde{t} \equiv \frac{t_{s}-t_{c}}{1+t_{c}}
$$

Household budget constraints can then be written:

$$
\mathbf{p}_{c} \mathbf{x}_{c}+(1+\tilde{t}) \mathbf{p}_{s} \mathbf{x}_{s}=0 \text {. }
$$

Define the Lagrange function:

$$
L_{h}=u(\cdot)-\hat{\alpha}\left(\mathbf{p}_{c} \mathbf{x}_{c}+(1+\tilde{t}) \mathbf{p}_{s} \mathbf{x}_{s}\right) .
$$


First-order conditions for households utility maximization are:

$$
\begin{array}{ll}
u_{i}=\hat{\alpha} p_{i}, & i=1, . ., m, \\
u_{i}=\hat{\alpha}(1+\tilde{t}) p_{i} & i=m+1, . ., n .
\end{array}
$$

The first-order conditions determine equilibrium demand and supply, $\mathbf{X}(\tilde{t}, e)=$ $h \mathbf{x}(\tilde{t}, e)$. The indirect utility function $v(\tilde{t}, e)$ follows, and we have that:

$$
\begin{aligned}
& v_{\tilde{t}}=-\hat{\alpha} \mathbf{p}_{s} \mathbf{x}_{s}, \\
& v_{e}=u_{e} .
\end{aligned}
$$

The government Lagrange function:

$$
L_{e}=h \cdot v(\tilde{t}, e)-\mu G(\mathbf{X}(\tilde{t}, e), e)
$$

Irrespective of whether the government maximizes with respect to the tax on consumption goods $t_{c}$ or the tax on factor supplies $t_{s}$, the first-order conditions become:

$$
\begin{aligned}
h u_{e} & =\mu\left(\sum_{i=1}^{n} G_{i} \frac{\partial X_{i}(\tilde{t}, e)}{\partial e}+G_{e}(\mathbf{X}(\tilde{t}, e), e)\right) \\
h v_{t}(\tilde{t}, e) & =\mu \sum_{i=1}^{n} G_{i} \frac{\partial X_{i}(\tilde{t}, e)}{\partial \tilde{t}} .
\end{aligned}
$$

From the household budget constraint we have that

$$
\sum_{i=1}^{n} p_{i} \frac{\partial X_{i}}{\partial e}=-\tilde{t} \sum_{i=m+1}^{n} p_{i} \frac{\partial X_{i}}{\partial e} \text { and that } \sum_{i=1}^{n} p_{i} \frac{\partial X_{i}}{\partial \tilde{t}}=-\mathbf{p}_{s} \mathbf{X}_{s}-t \sum_{i=m+1}^{n} p_{i} \frac{\partial X_{i}}{\partial \tilde{t}}
$$


Given that $G_{i}=p_{i}$ and that $v_{\tilde{t}}=-\hat{\alpha} \mathbf{p}_{s} \mathbf{x}_{s}$ we have:

$$
\begin{aligned}
\frac{\hat{\alpha}}{\mu} h \frac{u_{e}}{\hat{\alpha}} & =G_{e}(\mathbf{X}(\tilde{t}, e), e)-\tilde{t} \sum_{i=m+1}^{n} p_{i} \frac{\partial X_{i}}{\partial e}, \\
\frac{\hat{\alpha}}{\mu} & =1+\frac{\tilde{t}}{\mathbf{p}_{s} \mathbf{X}_{s}(\tilde{t}, e)} \sum_{i=m+1}^{n} p_{i} \frac{\partial X_{i}(\tilde{t}, e)}{\partial \tilde{t}} .
\end{aligned}
$$

The latter expression shows that the multiplier $\hat{\alpha} / \mu$ of the modified Samuelson

rule (A.3) depends on the size of the effective tax rate $\tilde{t}$, and is independent of the distribution of the tax between consumption and factor supply.

\section{B The division between the substitution and in- come effects}

This appendix follows up the discussion by Atkinson and Stern (1974) related to the division between the substitution effect and the income effect of a tax increase. To simplify, the two good case is considered. In the following, it is useful to consider good 1 as the consumer good and good 2 as the factor supplied. The first-best allocation of resources in the economy is then the solution to the two first-order conditions:

$$
\begin{aligned}
h \frac{u_{e}}{u_{1}} & =\frac{G_{e}}{G_{1}}, \\
h \frac{u_{e}}{u_{2}} & =\frac{G_{e}}{G_{2}},
\end{aligned}
$$

which together with Equation (1) determine optimal consumption of the private good, labour supply and optimal provision of the public good.

The households maximize utility $u(\mathbf{x}, e)$ given their budget constraint which now includes the endowment $I$ such that $\mathbf{q x}=I$. The Lagrange function can be written as follows:

$$
L_{h}=u(\mathbf{x}, e)-\tilde{\alpha}(\mathbf{q} \mathbf{x}-I) .
$$


The first-order conditions then become:

$$
u_{i}=\tilde{\alpha} q_{i} \quad \forall i
$$

The first-order conditions determine equilibrium demand for the private goods, $\mathbf{X}(\mathbf{q}, e, I)=h \mathbf{x}(\mathbf{q}, e, I)$. Furthermore, equilibrium consumption, together with provision of the public good, determines the equilibrium Lagrangian multiplier $\tilde{\alpha}(\mathbf{q}, e, I)$. The representative household's value function is given by $v(\mathbf{q}, e, I)$. The derivatives of the value functions with respect to public consumption and tax rates are given by:

$$
v_{e}=u_{e}, \quad v_{q_{i}}(\mathbf{q}, e, I)=-\tilde{\alpha} x_{i}, \forall i
$$

The government's Lagrange function can be written:

$$
L_{g}=h \cdot v(\mathbf{q}, e, I)-\mu(G(\mathbf{X}(\mathbf{q}, e, I), e)-h I)
$$

where $\mu$ is the Lagrange multiplier. The first-order conditions with respect to $e$, $t_{1}$, and $t_{2}$, respectively, are given by:

$$
\begin{aligned}
& h v_{e}-\mu\left[G_{1} \frac{\partial X_{1}}{\partial e}+G_{2} \frac{\partial X_{2}}{\partial e}+G_{e}\right]=0 . \\
& h v_{q_{1}}-\mu\left[G_{1} \frac{\partial X_{1}}{\partial q_{1}}+G_{2} \frac{\partial X_{2}}{\partial q_{1}}\right]=0 . \\
& h v_{q_{2}}-\mu\left[G_{1} \frac{\partial X_{1}}{\partial q_{2}}+G_{2} \frac{\partial X_{2}}{\partial q_{2}}\right]=0 .
\end{aligned}
$$

First, Equation (B.4) is reorganized. Divide both sides by $\mu$, use that $G_{i}=p_{i}$ and that it follows from the households' budget constraint that

$$
-\sum_{i} G_{i} \frac{\partial X_{i}}{\partial e}=\sum_{i} t_{i} \frac{\partial X_{i}}{\partial e}
$$

Furthermore, divide the left-hand side by $u_{1}$ and multiply by $\tilde{\alpha} q_{1}$, (recall that $\left.u_{1}=\tilde{\alpha} q_{1}\right)$, and divide both sides with $p_{1}=G_{1}$. Furthermore, assume, like Atkinson 
and Stern (1974), that the supply of public goods does not influence demand for the private goods. Then:

$$
\frac{\tilde{\alpha}}{\mu}\left(1+\frac{t_{1}}{p_{1}}\right) h \frac{u_{e}}{u_{1}}=\frac{G_{e}}{G_{1}} .
$$

Note that Equation (B.7) is the modified version of the Samuelson rule given by Equation (B.1) which applies irrespective of which goods are taxed. The first two terms on the left-hand side together represent the modification, the multiplier. The size of this multiplier is not sensitive to the choice of taxed good. ${ }^{8}$

To analyse the size of the multiplier of the modified Samuelsono, we first consider the case with a tax on good 1 , while we assume that $t_{2}=0$. By using that $v_{q_{1}}=-\tilde{\alpha} x_{1}$, that $G_{1}=p_{1}$, the households' budget constraint and Equation (B.5), the multiplier of Equation (B.7) can be specified as follows:

$$
\frac{\tilde{\alpha}}{\mu}\left(1+\frac{t_{1}}{p_{1}}\right)=\left(1+\frac{t_{1}}{p_{1}}\right)\left(1+\frac{t_{1}}{X_{1}} \frac{\partial X_{1}}{\partial q_{1}}\right) .
$$

Next, consider the case with a tax on good 2, while we assume that $t_{1}=0$. From Equation (B.6) it follows that the multiplier of Equation (B.7) now can be expressed as follows:

$$
\frac{\tilde{\alpha}}{\mu}=1+\frac{t_{2}}{X_{2}} \frac{\partial X_{2}}{\partial q_{2}}
$$

\footnotetext{
${ }^{8}$ It is useful to consider a slightly different method for reorganizing Equation (4). This time, divide, the left-hand side by $u_{2}$ and multiply by $\tilde{\alpha} q_{2}$, and divide both sides by $p_{2}=G_{2}$, also dividing both sides with $\mu$. This gives the following modified version of the Samuelson rule in Equation (B.2):

$$
\frac{\tilde{\alpha}}{\mu}\left(1+\frac{t_{2}}{p_{2}}\right) h \frac{u_{e}}{u_{2}}=\frac{G_{e}}{G_{2}} .
$$

Again, the first two terms on the left-hand side together represent the modification (the multiplier). Note that this multiplier equals the multiplier of Equation (B.7) only if $t_{1} / p_{1}=t_{2} / p_{2}$. Hence, with different taxation of good 1 and good 2, the two Samuelson rules should be modified differently to achieve second-best.
} 
Using the Slutsky equation this gives:

$$
\frac{\tilde{\alpha}}{\mu}=\underbrace{1 \underbrace{-t_{2} \frac{\partial X_{2}}{\partial I}}_{>0}}_{>1}+\underbrace{\frac{t_{2}}{X_{2}} \frac{\partial X_{2}^{c}}{\partial t_{2}}}_{<0} .
$$

where the index $c$ indicates that we are considering the compensated demand. Thus $\partial X_{2}^{c} / \partial t_{2}$ represents the substitution effect of the tax change.

Recall that $t_{2}<0$. If leisure is a normal good, then $\partial X_{2} / \partial I>0$. Thus, the second term on the right-hand side is positive. At the same time, the substitution effect means that $\partial X_{2}^{c} / \partial t_{2}>0$. Thus, if leisure is a normal good, then the substitution and income effects pull in different directions and we cannot conclude whether the expression on the right-hand side of (B.11) is less or greater than 1. If the income effect is stronger than the substitution effect, then the right-hand side of Equation (B.11) is greater than 1. If good 2 is labour supply, this means a backward bending labour supply curve, i.e. that Stiglitz and Dasgupta (1971) were right. However, Atkinson and Stern (1974) claimed that this result only applies if labour is taxed, not if consumption is taxed. We therefore return to the the case with a consumption tax $t_{1}>0$ while $t_{2}=0$. Again, using the Slutsky Equation, (B.9) can then be written:

$$
\frac{\tilde{\alpha}}{\mu}=\left(1+t_{1}\right) \underbrace{[\underbrace{1-t_{1} \frac{\partial X_{1}}{\partial I}}_{<0}+\underbrace{\frac{t_{1}}{X_{1}} \frac{\partial X_{1}^{c}}{\partial t_{1}}}_{<0}]}_{<1} .
$$

The square bracket in (B.12) is less than one, which leads Atkinson and Stern (1974) to conclude that with a consumption tax, the multiplier is always less than one. This implies that with a consumption tax, then MCF $>1$. This conclusion is reproduced by Håkonsen (1998) and Jacobs (2018), when they apply similar models to that in Atkinson and Stern (1974).

However, when the first factor on the right-hand side of (B.12), $\left(1+t_{1}\right)$, is taken into account, this cannot be guaranteed. In the case with a consumption 
tax, $\tilde{\alpha} / \mu$ can also be greater than one.

\section{References}

Atkinson, A. B., \& Stern, N. H. (1974). Pigou, taxation and public goods. Review of Economic Studies, 41(1), 119-128.

Ballard, C. L., \& Fullerton, D. (1992). Distortionary taxes and the provision of public goods. Journal of Economic Perspectives, 6(3), 117-131.

Boadway, R., \& Keen, M. (1993). Public goods, self-selection and optimal income taxation. International Economic Review, 34 (3), 463-478.

Browning, E., Gronberg, T., \& Liu, L. (2000). Alternative measures of the marginal cost of funds. Economic Inquiry, $38(4), 591-599$.

Christiansen, V. (2007). Two approaches to determine public good provision under distortionary taxation. National Tax Journal, 60(1), 25-43.

Dahlby, B. (1998). Progressive taxation and the social marginal cost of public funds. Journal of Public Economics, 67(1), 105-122.

Gahvari, F. (2006). On the marginal cost of public funds and the optimal provision of public goods. Journal of Public Economics, 90(6), 1251-1262.

Håkonsen, L. (1998). An investigation into alternative representations of the marginal cost of public funds. International Tax and Public Finance, 5(3), 329-343.

Jacobs, B. (2018). The marginal cost of public funds is one at the optimal tax system. International Tax and Public Finance, 25(4), 883-912.

Jacobs, B., \& de Mooij, R. A. (2015). Pigou meets mirrlees: On the irrelevance of tax distortions for the second-best pigouvian tax. Journal of Environmental Economics and Management, 71, 90-108.

Kaplow, L. (1996). The optimal supply of public goods and the distortionary cost of taxation. National Tax Journal, 49(4), 513-533.

Kleven, H. J., \& Kreiner, C. T. (2006). The marginal cost of public funds: Hours of work versus labor force participation. Journal of Public Economics, 90(1011), 1955-1973.

Kreiner, C. T., \& Verdelin, N. (2012). Optimal provision of public goods: A synthesis. The Scandinavian Journal of Economics, 114(2), 384-408. 
Pigou, A. C. (1947). A study in public finance (Third Edition ed.). London: MacMillan.

Samuelson, P. A. (1954). The pure theory of public expenditure. The Review of Economics and Statistics, 36(4), 387-389.

Sandmo, A. (1998). Redistribution and the marginal cost of public funds. Journal of Public Economics, 70 (3), 365-382.

Stiglitz, J. E., \& Dasgupta, P. (1971). Differential taxation, public goods, and economic efficiency. The Review of Economic Studies, 38(2), 151-174. 